\title{
Editorial
}

\section{Cultivated Legume Species}

\author{
Antonio M. De Ron, ${ }^{1}$ José I. Cubero, ${ }^{2}$ Shree P. Singh, ${ }^{3}$ and O. Mario Aguilar ${ }^{4}$ \\ ${ }^{1}$ MBG, Spanish National Research Council (CSIC), P.O. Box 28, 36080 Pontevedra, Spain \\ ${ }^{2}$ University of Cordova, P.O. Box 4084, 14080 Cordova, Spain \\ ${ }^{3}$ Kimberly Research and Extension Center, University of Idaho, Kimberly, ID 83341-5076, USA \\ ${ }^{4}$ Faculty of Sciences, IBBM, CONICET-University of La Plata, 1900 La Plata, Argentina
}

Correspondence should be addressed to Antonio M. De Ron; amderon@mbg.csic.es

Received 1 May 2013; Accepted 1 May 2013

Copyright ( $) 2013$ Antonio M. De Ron et al. This is an open access article distributed under the Creative Commons Attribution License, which permits unrestricted use, distribution, and reproduction in any medium, provided the original work is properly cited.

Legume species belong to the Fabaceae family and are characterized by their fruit, called usually pod. Members of the legume family, the Fabaceae or Leguminosae, fill critical niches in most terrestrial biomes. The family has traditionally been divided into three subfamilies: Caesalpinioideae, Mimosoideae, and Papilionoideae; this latter subfamily contains most of the major cultivated food and feed. Several legume species were domesticated by man, such as soybean, common bean, pea, faba bean, chickpea, lentil, peanut, pigeon pea, and cowpea. Some of these species are the basis for direct human nutrition, and animal feed. Immature pods or dry seeds of legumes are consumed, which have high protein content. Globally, grain legumes are the most relevant source of plant protein for human food and animal feed, but there are some constraints in their production, such as a poor adaptation, pest and diseases, and unstable yield.

Overweight or obesity, diabetes, metabolic syndrome, and cardiovascular diseases are exponentially growing human health issues. Nutritional and dietary actions are effective through a global shift in diet and reduced intake of energy-dense foods. Legume seeds represent one of the most promising foods to match these needs. This is due to their chemical composition and unique biological properties. Nonetheless, the nutritional value of legume seeds may be limited by the presence of antinutrient compounds whose reduction is desirable. Therefore, research activities aiming at exploring the possible formulation of grain legumes into easy-to-cook, ready-to-eat healthy food commodities are essential. To this purpose, the selection and optimal knowledge of the starting materials and the specific roles played by single seed components or fractions are crucial to envisage and design innovative food applications or to improve the traditional methods.

Legumes contribute to a sustainable improvement of environment when grown in mixture or rotations with other crops due to their ability to fix atmospheric molecular nitrogen in symbiotic association with rhizobia, and their effects on soil, control of weeds, and to serve as pollinators and cover crops. Legumes play a key role in the diversification and sustainable intensification of agriculture, particularly during climate change, sustainability of the food and feed chain, and meeting requirements of citizens for safe, healthy, and affordable food by preventing diet-related diseases and depression.

Crop production systems involving legumes represent a cheaper and more sustainable alternative to conventional practices by biological nitrogen fixation, thus reducing the use of industrially produced nitrogen fertilizers to improve yield of field crops. Improvement of $\mathrm{N}$ management is needed not only to optimize economic returns to farmers but also to minimize environmental concerns associated with the use of chemical fertilizers, namely, leaching problems and water pollution. Intercropping or crop rotation including legumes is a promising strategy for more sustainable crop production in many agricultural systems. For example, in a crop rotation, cultivated legumes can be used in between the cereals or other crops (e.g., vegetables) and have the potential of reducing biotic stresses, improving nutrient use efficiency, and contributing to increase yield and yield stability.

Currently global research projects involving genomic and genetic approaches to reach a deeper knowledge of economically important legume species are in progress, aimed to the genetic improvement in the near future. 
This special issue includes six research articles related to the above mentioned topics.

"Changes in protein, nonnutritional factors, and antioxidant capacity during germination of L. campestris seeds" (C. Jiménez Martínez et al.) discusses that concentration of phenolic compounds increased $450 \%$ during germination from the original level in the seed. Thus, germination could be used to produce legume foods for human consumption with better nutraceutical properties.

"Effect of soil pH on the alkaloid content of Lupinus angustifolius" (G. Jansen et al.) presented results that clearly showed that the alkaloid content was significantly influenced by the soil $\mathrm{pH}$. Also, genotypic differences in response to different $\mathrm{pH}$ values in the soil were observed.

"Growth and physiological responses of Phaseolus species to salinity stress" (J. S. Bayuelo-Jiménez et al.) shows that despite some changes in soluble carbohydrate accumulation induced by salt stress being detected, no consistent association with osmotic adjustment could be found in this study. Therefore, the authors suggest that tolerance to salt stress is largely unrelated to carbohydrate accumulation in Phaseolus species.

"Genetic transformation of common bean (Phaseolus vulgaris L.) with the Gus color marker, the Bar herbicide resistance, and the barley (Hordeum vulgare) HVA1 drought tolerance genes" (K. Kwapata et al.) discusses that some common bean varieties were genetically transformed via the biolistic bombardment of the apical shoot meristem primordia. Transgenes included Gus color marker which visually confirmed transgenic events, the Bar herbicide resistance selectable marker used for in vitro selection of transformed cells and which confirmed Liberty herbicide resistant plants, and the barley (Hordeum vulgare) late embryogenesis abundant protein (HVA1) which conferred drought tolerance with a corresponding increase in root length of transgenic plants.

"Role of pigeonpea cultivation on soil fertility and farming system sustainability in Ghana" (S. Adjei-Nsiah) shows that despite its importance, the potential of pigeonpea as a soil fertility improvement crop has not been exploited to any appreciable extent and the amount of land cultivated to pigeonpea in Ghana is very negligible. One conclusion of this study is that in order to promote the cultivation of pigeonpea in Ghana, there is the need to introduce varieties that combine early maturity with high yields and other desirable traits based on farmers preferences.

"Quantitative trait loci analysis of folate content in dry beans, Phaseolus vulgaris L." (S. Khanal et al.) shows that folates are essential vitamins and folate deficiencies may lead to a number of health problems. Among the different forms of folates, 5-methylterahydrofolate (5MTHF) comprises more than $80 \%$ of the total folate in dry beans. A single marker QTL analysis identified three QTL for total folate and 5MTHF contents in the first measurement and one marker for the total folate in the second measurement in the $F_{2}$. These QTLs had significant dominance effects and individually accounted for 7.7 to $10.5 \%$ of total phenotypic variance. The total phenotypic variance explained by the four QTL was $18 \%$ for $5 \mathrm{MTHF}$ and
$19 \%$ for total folate in the first measurement, but only $8 \%$ for total folate in the second measurement.

Antonio M. De Ron José I. Cubero Shree P. Singh O. Mario Aguilar 


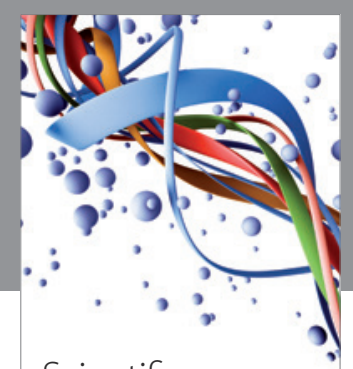

Scientifica
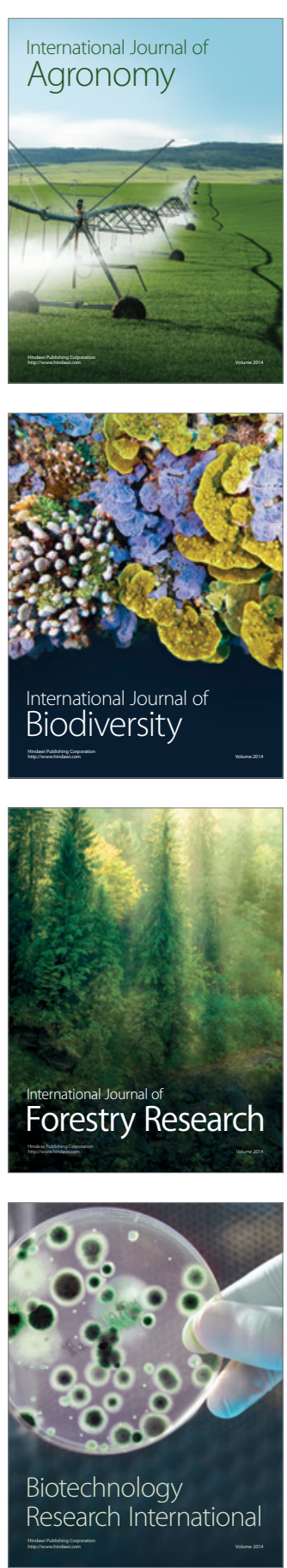
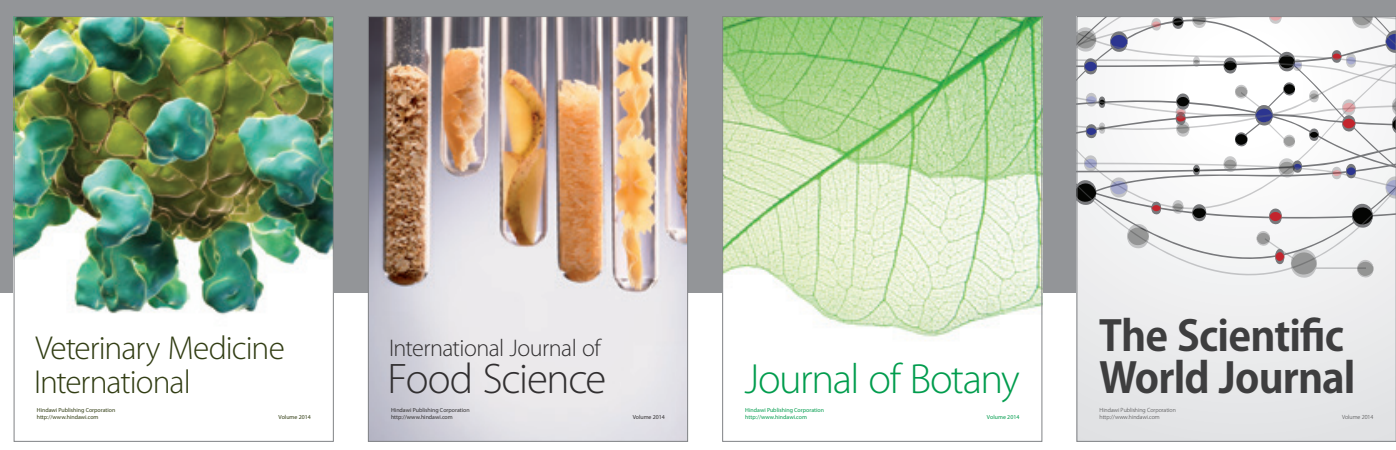

The Scientific World Journal
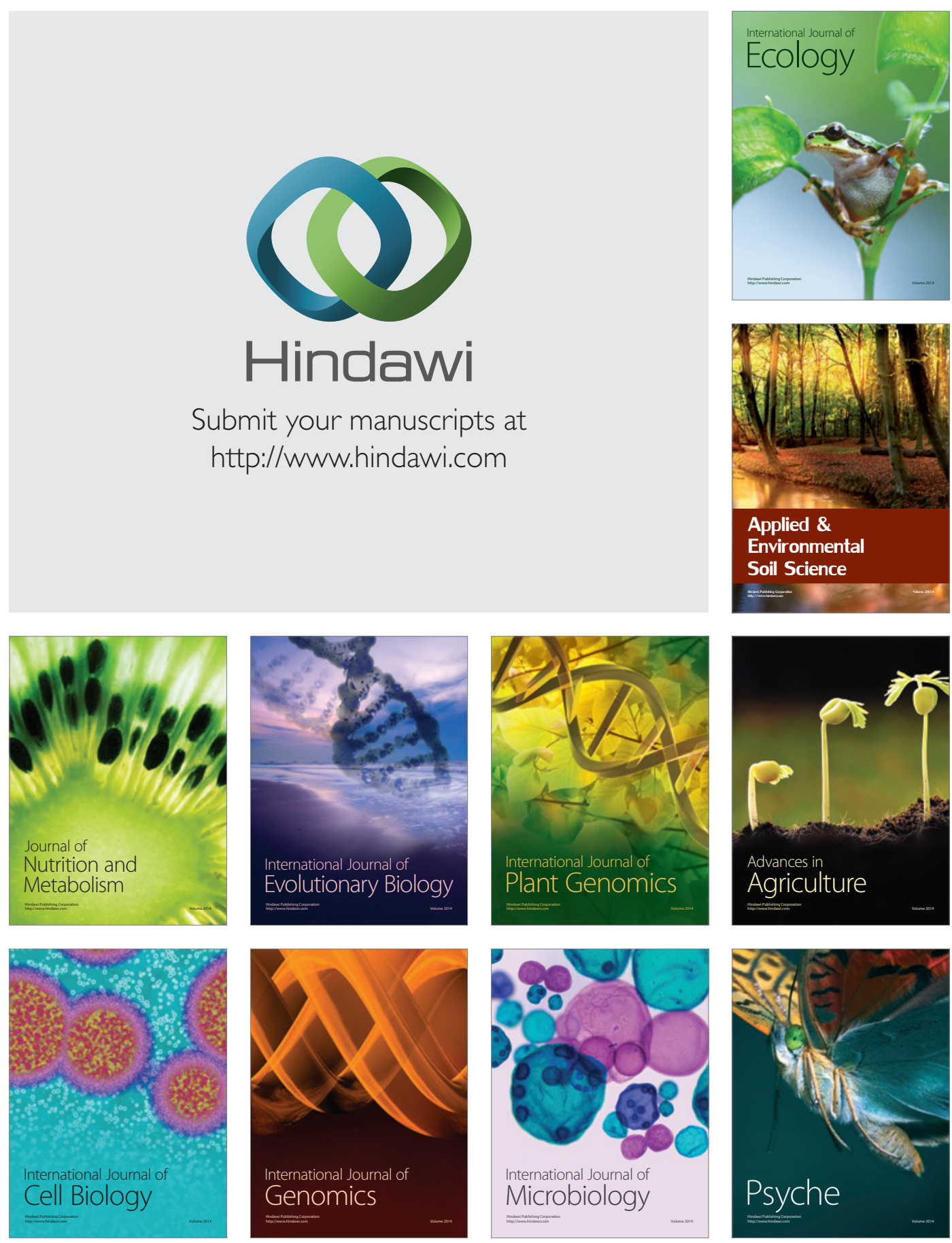